\title{
Improved Detection of Tilletia indica Teliospores in Seed or Soil by Elimination of Contaminating Microorganisms with Acidic Electrolyzed Water
}

\author{
M. R. Bonde, S. E. Nester, N. W. Schaad, R. D. Frederick, and D. G. Luster, USDA-ARS, Foreign Disease- \\ Weed Science Research Unit, Fort Detrick, MD 21702
}

\begin{abstract}
Bonde, M. R., Nester, S. E., Schaad, N. W., Frederick, R. D., and Luster, D. G. 2003. Improved detection of Tilletia indica teliospores in seed or soil by elimination of contaminating microorganisms with acidic electrolyzed water. Plant Dis. 87:712-718.

Acidic electrolyzed water (AEW) is a germicidal product of electrolysis of a dilute solution (e.g., $0.4 \% \mathrm{vol} / \mathrm{vol}$ ) of sodium chloride. This solution can be used to disinfest wheat seed or soil samples being tested for teliospores of Tilletia indica, causal agent of Karnal bunt, without risk of damaging the teliospores. The AEW used in this study had a pH of 2.5 to 2.8 and oxidationreduction potential of approximately $1,130 \mathrm{mV}$. In simulations of routine extractions of wheat seed to detect teliospores of $T$. indica, the effectiveness of a 30-min AEW treatment was compared with a 2-min $0.4 \%$ sodium hypochlorite $(\mathrm{NaOCl})$ treatment to eradicate bacteria and nonsmut fungi. Each treatment reduced bacterial and fungal populations in wheat seed extracts by 6 to $7 \log _{10}$ units when determined on $2 \%$ water agar with antibiotics. Reductions of $5 \log _{10}$ units or more were observed on other media. $\mathrm{NaOCl}$ and AEW also were very effective at eliminating bacteria and fungi from soil extracts. In studies to detect and quantitate $T$. indica teliospores in soil, AEW was nearly $100 \%$ effective at eliminating all nonsmut organisms. Free chlorine levels in AEW were very low, suggesting that compounds other than those with chlorine play a significant role in sanitation by AEW. The low $\mathrm{pH}$ of AEW was shown to contribute substantially to the effectiveness of AEW to reduce microorganisms. A standardized protocol is described for a 30-min AEW treatment of wheat seed washes or soil extracts to eliminate contaminating microorganisms. A significant advantage of the use of AEW over $\mathrm{NaOCl}$ is that, with AEW, teliospore germination is not reduced and usually is stimulated, whereas teliospore germination declines after contact with $\mathrm{NaOCl}$. The protocol facilitates detection and enumeration of viable teliospores of $T$. indica in wheat seed or soil and the isolation of pure cultures for identification by polymerase chain reaction. The germicidal effects of AEW, as demonstrated in this study, illustrate the potential of AEW as an alternative to presently used seed disinfestants.
\end{abstract}

Additional keywords: disinfestant, Karnal bunt, sodium hypochlorite, superoxidized water

The objective of this study was to determine the efficacy of acidic electrolyzed water (AEW) to eliminate microorganisms other than Tilletia indica Mitra teliospores from wheat seed and soil extracts. The teliospores then can be identified by a polymerase chain reaction $(\mathrm{PCR})$ test $(9,10,26)$. Growth of contaminants can

Corresponding author: M. R. Bonde

E-mail: mbonde@fdwsr.ars.usda.gov

The use of trade, firm, or corporation names in this article is for the information and convenience of the reader. Such use does not constitute an official endorsement or approval by the United States Department of Agriculture or the Agricultural Research Service of any product or service to the exclusion of others that may be suitable.

Accepted for publication 3 February 2003.

Publication no. D-2003-0414-02R

This article is in the public domain and not copyrightable. It may be freely reprinted with customary crediting of the source. The American Phytopathological Society, 2003. obscure germinating $T$. indica teliospores and inhibit teliospore germination (M. R. Bonde and S. E. Nester, personal observation). The AEW treatment is part of a proven protocol to detect $T$. indica teliospores in wheat seed samples using a bioPCR based technique (23). However, the level of germicidal effectiveness of AEW for reducing contaminating microorganisms in wheat (or soil) extracts when testing for $T$. indica has not been reported.

Karnal bunt of wheat first was discovered in India in 1930 (20) and since has been found in Pakistan, Nepal, Iraq, Afghanistan (5), northwest Mexico (8), southwest United States (34), and South Africa (7). Although Karnal bunt usually causes only minor yield and quality reductions $(1,11)$, it is the subject of strict international quarantines (5). Teliospores of $T$. indica detected in a wheat shipment can cause rejection of the consignment by certain countries. As a result, USDA initiated a Karnal bunt research program in 1982 (5,25). Immediately following the discovery of Karnal bunt in Arizona and California in 1996 (34), extensive field surveys were conducted in those states, and a national Karnal bunt survey was initiated to determine the extent to which Karnal bunt might be present in harvested grain in other areas of the country.

Differentiation of $T$. indica from morphologically similar species sometimes required a method other than microscopy (5). For example, Tilletia walkeri from rye grass, and T. horrida from rice, have teliospores that are morphologically similar to those of $T$. indica, which sometimes are present as contaminants in harvested wheat grain (6). The method we used for species determination was based upon the PCR using $T$. indica species-specific DNA primers, and required germination of suspect teliospores to obtain sufficient DNA for the test (10). As part of the original protocol to germinate teliospores, the extract that was obtained by size-selective sieving of grain samples was treated for 2 min with $0.4 \%$ sodium hypochlorite $(\mathrm{NaOCl})(21)$. The $\mathrm{NaOCl}$ treatment eliminated most other contaminating microorganisms whose DNA could interfere with PCR assays, and stimulated teliospore germination (3). However, a major drawback was that bunt teliospores sometimes would not germinate due to dormancy or possibly due to damage by the harsh $\mathrm{NaOCl}$ treatment. Lack of germination could retard timely identifications.

At the time of the National Karnal Bunt Survey in 1996 and 1997, the United States Department of Agriculture-Agricultural Research Service (USDA-ARS) at Fort Detrick was testing AEW as a means of decontaminating harvested grain potentially contaminated with $T$. indica teliospores. AEW has been referred to by many names, including superoxidized water (24), electrolyzed saline solution (32), and functional water (17). Most research on its sanitizing capabilities has been conducted with bacteria $(14,24,28-30)$. In medical practice in Japan, AEW is used to treat mediastinitis infection after cardiovascular surgery (13).

AEW is a product of electrolysis of a dilute solution of sodium chloride and contains a low concentration of hypochlorous acid, which is a very effective sanitizer at low $\mathrm{pH}$ (31). In preliminary tests in our laboratory, AEW treatments of 20 to 30 min killed bacteria and fungi, including Aspergillus, Cladosporium, and Penicillium spp., while stimulating germination of teliospores of T. indica (4). However, at 
that time, we did not quantitatively determine AEW's effectiveness at reducing microbial populations.

In 1998, a Karnal bunt teliospore survival study was initiated in field plots in several locations in the United States (M. R. Bonde, S. E. Nester, M. W. Olsen, and D. K. Berner, unreported data). This study required testing teliospores for viability at specific intervals after placing $T$. indicainfested soil contained in specially designed quarantine containers in the field. AEW became an important part of the protocol for eliminating contaminants from teliospores extracted from soil samples in order to test for teliospore viability on a germination medium. We report here results of studies that quantitatively compare efficacies of $\mathrm{AEW}$ and $0.4 \% \mathrm{NaOCl}$ to eradicate contaminating bacteria and fungi from wheat seed or soil extracts. This information is required to make informed decisions on appropriate methods to be used in assays. Extrapolation from our results suggests that AEW may have great potential for other applications in plant pathology.

All research with $T$. indica was done with appropriate permission from the U.S. government, Maryland, and Arizona. Teliospore viability tests were conducted in the plant pathogen containment facility at USDA, Frederick, MD (19).

\section{MATERIALS AND METHODS}

Preparation of AEW and $\mathrm{NaOCl}$ solutions. AEW was generated by electrolysis of water in a Super Oxseed Laboratory JED 020 apparatus (Proton Laboratories, Inc., Alameda, CA), in which an electric current was passed through a dilute solution of sodium chloride (3). Sodium chloride $(0.70 \mathrm{~g})$ (Sigma-Aldrich, St. Louis) was dissolved in 4 liters of water; 2 liters each were poured into the anode and cathode compartments, respectively; and electrolysis was allowed to proceed for $15 \mathrm{~min}$. AEW was generated in the anode compartment and alkaline water in the cathode compartment. The $\mathrm{pH}$, oxidation-reduction potential (ORP), and free chlorine content of the AEW produced were determined at the beginning and end of the treatment phase of experiments using a $\mathrm{pH}$ meter, redox meter, and spectrophotometric analysis at $528 \mathrm{~nm}$ using $N, N$-diethyl- $p$ phenylenediamine (31), respectively. Fresh AEW was prepared on the day in which it was required for an experiment.

A fresh $0.4 \% \quad(\mathrm{vol} / \mathrm{vol})$ solution of $\mathrm{NaOCl}$ (approximately $\mathrm{pH} 10.3$ ) was prepared for each experiment by diluting a $5.25 \%$ solution of a commercial bleach with distilled water. The $\mathrm{pH}$ and free chlorine content were determined at the beginning and end of experiments as described above.

Comparison of $\mathrm{AEW}$ and $\mathrm{NaOCl}$ for eradicating bacteria and fungi from wheat seed washes. Nine 50-g Karnal bunt-free wheat seed samples from each of six wheat lots from several western and midwestern states were extracted using the size-selective sieving method (21). After incubating in $14 \mathrm{ml}$ of water overnight at $20^{\circ} \mathrm{C}$, followed by centrifugation, the wheat wash pellet of each of three samples for each of six wheat lots was treated with $14 \mathrm{ml}$ of AEW for $30 \mathrm{~min}$ with periodic shaking by hand, and three samples of each wheat lot were treated with $14 \mathrm{ml}$ of $0.4 \%$ $\mathrm{NaOCl}$ for $2 \mathrm{~min}$. Three wheat wash samples from each lot were left untreated to serve as controls. After treatment, each sample wash was centrifuged for $1 \mathrm{~min}$ at $200 \times g$, and pellets were washed twice with sterile distilled water and resuspended in $200 \mu \mathrm{l}$ of sterile distilled water. Each suspension was spread onto a square petri dish, 100 by 100 by $15 \mathrm{~mm}$ in size (with 13 -mm wide grids) of $2 \%$ water agar with antibiotic containing streptomycin sulfate and ampicillin sodium salt (AWA) at 100 $\mathrm{mg} /$ liter each. All plates were incubated at $20^{\circ} \mathrm{C}$ and a 12-h day (with white fluorescent light), and examined after 14 days at $\times 10$ magnification by means of a dissecting microscope to determine numbers of $\mathrm{CFU}$ of bacteria and fungi.

The experiment was repeated, but with slight modification (Table 1). AEW-treated samples from eight lots of wheat seed from Kansas, where Karnal bunt has never been detected, were gently rocked on a rocker (Speci-Mix; Barnstead/Thermolyne, Dubuque, IA) for $30 \mathrm{~min}$. Following treatment with AEW or $\mathrm{NaOCl}$, samples were centrifuged, washed in water, and spread onto AWA agar as before.

An additional experiment was conducted on nutrient media to quantitate the effectiveness of AEW and $0.4 \% \mathrm{NaOCl}$ for specific control of bacteria or fungi. Eighteen 50-g samples from each of three wheat lots (Table 2) were extracted as before. Six samples from each lot were treated for 30 min with AEW with continuous gentle rocking as before, six samples were treated for 2 min with $0.4 \% \mathrm{NaOCl}$, and six samples received no treatment to serve as controls. The extracts were washed, centrifuged, and, following serial dilutions from $10^{-2}$ to $10^{-4}$ of the controls, pellets were resuspended in $200 \mu \mathrm{l}$ of sterile distilled water as before. Half of the suspensions of each treatment were spread onto one dish (per each dilution/replicate/treatment) of potato dextrose agar (Difco Laboratories, Detroit) containing streptomycin sulfate and ampicillin sodium salt (PDAA) at 100 $\mathrm{mg} /$ liter each for total detection of fungi, and half onto single dishes of nutrient broth yeast (NBY) agar (22) containing cycloheximide (referred to here as NBYC agar) at $200 \mathrm{mg} / \mathrm{liter}$ for total detection of bacteria. The Petri dishes were incubated at $20^{\circ} \mathrm{C}$ as above and examined after 6 days. Yeast colonies, when detected, were included with the bacteria to simplify differentiation.

Comparison of $\mathrm{AEW}$ and $\mathrm{NaOCl}$ for eradicating bacteria and fungi in soil extracts. Nine separate 3-g Karnal buntfree soil samples from each of four locations without disease, including Tucson, AZ; Tifton, GA; Topeka, KS; and Frederick, MD; were extracted by means of a modification of the sucrose centrifugation technique described by Babadoost and Mathre (2). In brief, a 3-g soil sample was placed in a $250-\mathrm{ml}$ beaker and sufficient distilled water added to cover the soil. Then the soil was allowed to sit overnight at room temperature. The next day, $100 \mathrm{ml}$ of distilled water containing 1 drop Tween 20/100 $\mathrm{ml}$ was added to the soil in each beaker and stirred for 3 min with a magnetic stirrer. The suspension was filtered through a $53-\mu \mathrm{m}$ pore-size nylon screen (first wet screen) and the filter was rinsed with a fine stream of water until $1,000 \mathrm{ml}$ was collected. The suspension then was

Table 1. Numbers of contaminants present in wheat seed washes after treatment with acidic electrolyzed water $(\mathrm{AEW})$ or $0.4 \%$ sodium hypochlorite $(\mathrm{NaOCl})^{\mathrm{a}}$

\begin{tabular}{|c|c|c|c|c|c|}
\hline \multirow[b]{2}{*}{ Wheat lot } & \multirow[b]{2}{*}{ Control $(\mathrm{CFU})^{\mathrm{b}}$} & \multicolumn{2}{|c|}{$30 \mathrm{~min}$, AEW } & \multicolumn{2}{|c|}{$2 \mathrm{~min}, 0.4 \% \mathrm{NaOCl}$} \\
\hline & & $\mathbf{C F U}^{\mathbf{b}}$ & Reduction $(\%)^{\mathrm{c}}$ & $\mathbf{C F U}^{\mathrm{b}}$ & Reduction (\%) \\
\hline Kansas 2237 & 48.55 & 0.3 & 99.9999 & 0.0 & 100.0000 \\
\hline Kansas 2245 & 16.95 & 0.0 & 100.0000 & 0.0 & 100.0000 \\
\hline Kansas 2236 & 15.86 & 0.0 & 100.0000 & 0.0 & 100.0000 \\
\hline Kansas 2384 & 3.67 & 0.0 & 100.0000 & 0.0 & 100.0000 \\
\hline Kansas 2225 & 10.84 & 0.0 & 100.0000 & 0.0 & 100.0000 \\
\hline Kansas 2250 & 9.52 & 0.0 & 100.0000 & 0.0 & 100.0000 \\
\hline Kansas 2228 & 1.19 & 0.0 & 100.0000 & 0.0 & 100.0000 \\
\hline Kansas 2231 & 3.99 & 0.0 & 100.0000 & 0.0 & 100.0000 \\
\hline Average & 13.82 & 0.04 & >99.9999 & 0.0 & 100.0000 \\
\hline
\end{tabular}

a Wheat wash samples were extracted from each of nine separate 50-g wheat samples of eight wheat lots by means of size-selective sieving (21). For each lot, three samples were treated with AEW for 30 min with continuous gentle rocking, three samples were treated for 2 min with $0.4 \% \mathrm{NaOCl}$, and three samples had no treatment (control). Washes were spread onto $2 \%$ water agar containing ampicillin sodium salt and streptomycin sulfate at $100 \mathrm{mg} /$ liter each in petri dishes.

${ }^{\mathrm{b}}$ Figures represent the average number of $\mathrm{CFU} \times 10^{4}$ of fungi and bacteria present as colonies 14 days after seeding petri dishes with extracts from three wheat samples from a lot and incubating at $20^{\circ} \mathrm{C}$.

${ }^{\mathrm{c}}$ Percent reduction is the average percent decrease in CFU for three replicate samples treated with $\mathrm{AEW}$ or $\mathrm{NaOCl}$ compared with the control (no treatment) samples. 
poured through a 20- $\mu \mathrm{m}$ nylon screen (second wet screen) to collect the 20- to $53-\mu \mathrm{m}$-diameter fraction of debris, which then was washed from the screen into a 50$\mathrm{ml}$ centrifuge tube and centrifuged at 1,200 $\times g$ for $3 \mathrm{~min}$. The liquid was decanted, and the pellet was suspended in $35 \mathrm{ml}$ of $80 \%$ sucrose, centrifuged at $200 \times g$ for 40 s, and decanted onto a $20-\mu \mathrm{m}$ screen. The residual pellet was extracted three more times. The residue collected on the screen was washed by means of a fine stream of water, transferred into a 15-ml centrifuge tube, brought to $14 \mathrm{ml}$ with distilled water, and incubated at $20^{\circ} \mathrm{C}$ overnight, with $12 \mathrm{~h}$ of light.

The soil extracts for three samples were treated with AEW for 30 min with gentle rocking as described above; three samples were treated with $0.4 \% \mathrm{NaOCl}$ for 2 min, and three were not treated (controls). Following serial dilutions on the controls, each extract was spread onto AWA agar as above. The petri dishes were incubated at $20^{\circ} \mathrm{C}$ with a 12 -h day as described above, then examined after 6 days at $\times 10$ magnification to determine numbers of CFU of bacteria and fungi.

To specifically quantify the effectiveness of $\mathrm{AEW}$ and $0.4 \% \mathrm{NaOCl}$ to reduce bacteria or fungi populations in soil extracts as measured on media that promote growth, 18 3-g soil samples were extracted, pooled, mixed, and redivided. Six each of the redivided extracts were treated for $30 \mathrm{~min}$ with $\mathrm{AEW}$, six were treated for 2 min with $0.4 \% \mathrm{NaOCl}$, and six were not treated (controls). After treatment, the extracted pellets were suspended in $200 \mu$ of sterile distilled water, then diluted serially as described above. Undiluted samples and 200- $\mu$ l aliquots of dilutions were spread onto PDAA to detect total fungi, or onto NBYC to detect total bacteria. All petri dishes were incubated at $20^{\circ} \mathrm{C}$ as above, then examined at 5 days to determine the number of CFU of fungi and bacteria. The experiment initially was repeated four times with 18 samples each for a sand clay loam from Arizona, a sand loam from Georgia, a silt clay loam from Kansas, and a clay loam from Maryland. The experiment with the Arizona soil was repeated once and the experiment with the Maryland soil twice.

Eradication of nonsmut microorganisms in extracts of $\boldsymbol{T}$. indica-infested soil. Teliospores obtained in 1996 from Sonora, Mexico, were scraped by means of a dissecting needle from infected seed while immersed in sterile distilled water with 1 drop of Tween 20 surfactant per $100 \mathrm{ml}$. These teliospores were suspended in water that contained 1 drop of Tween 20 surfactant in $100 \mathrm{ml}$ of water, passed through a $53-\mu \mathrm{m}$ pore-size polyester screen, and rinsed with surfactant-containing water on a $20-\mu \mathrm{m}$ pore-size stainless steel screen, which eliminated small, immature teliospores. Teliospores retained on the $20-\mu \mathrm{m}$ screen were suspended in approximately $50 \mathrm{ml}$ of the surfactant-containing water by stirring with a magnetic stirrer, and enumerated by means of a hemacytometer. A $45-\mu \mathrm{l}$ aliquot containing 10,000 teliospores was added to each of approximately 1,000 polyester mesh bags, each containing $3 \mathrm{~g}$ of soil. The bags were glued and sewn shut and sent to Tucson, AZ.

At the Arizona Campus Agricultural Center, Tucson, bags containing infested soil were placed in two irrigated and two nonirrigated field plots. In each plot, 72 bags were buried at depths of 2,10 , or 20 $\mathrm{cm}$. Three bags from each depth were recovered from each plot and sent to Frederick, MD every 6 months.

Upon arrival in Frederick, teliospores were extracted from soil by a modification of the technique of Babadoost and Mathre (2) and treated with AEW for $30 \mathrm{~min}$ as previously described. The final pellet was resuspended in $2 \mathrm{ml}$ of sterile $0.1 \%$ water agar to keep teliospores in suspension, and concentration of teliospores was determined by means of a Howard Mold Counting Chamber (Hauser Scientific Co., Horsham, PA). An aliquot calculated to contain 100 teliospores was placed on $2 \%$ water agar containing streptomycin sulfate and ampicillin sodium salt (AWA) at 100 $\mathrm{mg} / \mathrm{liter}$ each in each of six 100-by-100- $\mathrm{mm}$ petri dishes. The volume of liquid per petri dish was brought to $200 \mu \mathrm{l}$ and spread over the entire surface of the semisolid medium. Petri dishes were incubated at $20^{\circ} \mathrm{C}$ and a 12-h day (cool white light), then examined at $\times 10$ magnification after 10 to 12 days to determine numbers of $T$. indica colonies and of other microbial colonies. The procedure was repeated at 6month intervals for 42 months.

Effects of high acidic conditions on viability of bacteria and fungi extracted from wheat seed. Twenty durum (cv. Renville) 50-g wheat samples were extracted separately by size-selective sieving (21). The extracts were pooled, the volume adjusted to $20 \mathrm{ml}$ using sterile distilled water, and vortexed, after which 1-ml aliquots were dispensed into 18 disposable $15-\mathrm{ml}$ centrifuge tubes. After incubation at $20^{\circ} \mathrm{C}$ overnight, followed by centrifugation, three samples each were made up to $14 \mathrm{ml}$, either with AEW and gently rocked $30 \mathrm{~min}$ as described above, or with $0.4 \% \mathrm{NaOCl}$ and treated for $2 \mathrm{~min}$. Six samples were brought to $14 \mathrm{ml}$ with $0.05 \mathrm{M}$ glycine- $\mathrm{HCl}$ buffer, pH 2.5 (12), and six were not treated (controls). Treating solutions were removed via centrifugation, samples were rinsed and brought to $200 \mu \mathrm{l}$ with sterile distilled water, and serial dilutions were made for the $\mathrm{pH} 2.5$ buffer and control samples. All sample solutions, and 200- $\mu$ l aliquots of their dilutions, were spread onto single PDAA petri dishes (100 by 100 by $15 \mathrm{~mm}$ ) and incubated as previously described. After 5 days, the number of CFU of fungi and bacteria were counted to compare the effect of acidic conditions alone to treatment with $\mathrm{NaOCl}$ or AEW on their survival. The experiment was conducted twice.

Effect of AEW solution age on pH, ORP, free chlorine content, and sanitation effectiveness. AEW was produced on separate days using the protocol previously described and aged in clear glass bottles at room temperature on a laboratory shelf. On the day of the experiment, AEW aged 0, 1, $2,6,10,13,15$, or 34 days was tested to determine $\mathrm{pH}$, ORP, and free chlorine

Table 2. Numbers of fungi and bacteria CFU present in wheat seed extracts after treatment with acidic electrolyzed water (AEW) or sodium hypochlorite $(\mathrm{NaOCl})^{\mathrm{a}}$

\begin{tabular}{|c|c|c|c|c|c|c|c|c|}
\hline \multirow[b]{2}{*}{ Wheat lot } & \multicolumn{2}{|c|}{ Control } & \multicolumn{3}{|c|}{30 min, AEW } & \multicolumn{3}{|c|}{$2 \mathrm{~min}, 0.4 \% \mathrm{NaOCl}$} \\
\hline & Fungi $^{\text {b }}$ & Bacteria $^{\mathbf{b}}$ & Fungi $^{b}$ & Bacteria $^{\mathbf{b}}$ & Reduction $(\%)^{\mathrm{c}}$ & Fungi $^{b}$ & Bacteria $^{\mathbf{b}}$ & Reduction (\%) \\
\hline Grandin H. R. S. & 0.4 & 20.0 & 0.0 & 0.3 & 99.9999 & 0.3 & 0.7 & 99.9995 \\
\hline Kansas \#2249 & 2.3 & 8.5 & 0.7 & 0.5 & 99.9986 & 0.0 & 2.0 & 99.9977 \\
\hline Kansas \#2348 & TNTC $^{d}$ & 62.7 & 0.0 & 0.0 & 100.0 & 0.3 & 0.3 & >99.9999 \\
\hline Average & 1.4 & 30.4 & 0.2 & 0.3 & 99.9995 & 0.2 & 1.0 & 99.9990 \\
\hline
\end{tabular}

${ }^{a}$ Wheat wash samples were extracted from each of 18 separate 50-g wheat samples of three wheat lots by means of size-selective sieving (21). Six wash samples were treated with AEW for 30 min with continuous gentle rocking, six wash samples were treated 2 min with $0.4 \% \mathrm{NaOCl}$, and six received no treatment (control). Three sample washes for each treatment of each wheat lot were spread onto single dishes of potato dextrose agar with ampicillin sodium salt and streptomycin sulfate (PDAA) at $100 \mathrm{mg} / \mathrm{liter}$ each and three sample washes onto nutrient broth yeast agar containing cycloheximide (NBYC) at $200 \mathrm{mg} / \mathrm{liter}$.

${ }^{\mathrm{b}}$ Each figure represents the average number of CFU $\times 10^{3}$ of fungi on PDAA and CFU $\times 10^{4}$ of bacteria on NBYC 6 days after seeding petri dishes with extracts from three grain samples from a wheat lot.

${ }^{c}$ Percent reduction is based on decrease in average contaminant colony numbers when compared with the untreated samples.

d Too numerous to count. 
content. Each AEW sample and freshly prepared $\mathrm{NaOCl}$ solution $(0.4 \% \mathrm{vol} / \mathrm{vol})$ was used to treat three pooled and redivided sample extracts from three $50-\mathrm{g}$ durum (cv. Renville) wheat samples as previously described. Three pooled and redivided sample extracts were not treated to serve as controls. The debris from each sample was then spread onto one 100-by100-by-15-mm PDAA petri dish and incubated at $20^{\circ} \mathrm{C}$ with a 12 -h light and dark cycle. Populations of bacteria and fungi were counted up to 5 weeks after seeding petri dishes. The experiment was done twice.

\section{RESULTS}

In an experiment in which treated washes from wheat seed samples from several areas of the United States were rocked intermittently, $\mathrm{NaOCl}$ and $\mathrm{AEW}$ eliminated 100 and $99.998 \%$ of contaminants, respectively, detected on AWA. In experiments with continuous rocking, $\mathrm{NaOCl}$ and AEW eliminated 100 and $>99.9999 \%$ (6 to $7 \log _{10}$ reduction) of bacteria and fungi, respectively, on AWA dishes (Table 1). Of a total of 24 samples treated with AEW, only one microbial (fungal) colony grew on the medium. In further experiments, based on number of colonies of bacteria and fungi on PDAA and NBYC, respectively, specific for bacteria and fungi, both $\mathrm{NaOCl}$ and AEW eliminated $99.999 \%$ of contaminating bacteria and fungi (Table 2). When repeated once with the Arizona soil and twice with the Maryland soil, results for reduction in microorganisms was within 1 $\log _{10}$ units.

AEW and $\mathrm{NaOCl}$ each eliminated more than $99.6 \%$ of all contaminating bacteria and fungi from extracts of four different soils on AWA (Table 3). In an identical replicated experiment, $99.9998 \%$ (5 to 6 $\log _{10}$ reduction) of all bacteria and fungi were eliminated by each treatment. However, in a study in which PDAA was used to score total viable counts of fungi, and NBYC total viable counts of bacteria, 98.47 to $99.05 \%$ of fungi and 99.64 to $99.94 \%$ of bacteria were eliminated by the AEW treatment, and 97.12 to $99.10 \%$ of fungi and 79.94 to $98.23 \%$ of bacteria were eliminated by the $0.4 \% \mathrm{NaOCl}$ treatment (Table 4).

Among extracts from nearly 2,000 $\mathrm{T}$. indica-infested soil samples, treated for 30 min with AEW, spread onto AWA, and incubated for 10 to 12 days, $12.3 \%$ developed one to three non- $T$. indica colonies. This equaled approximately one contaminant per 406 T. indica teliospores in a soil sample extract.

In two experiments, a comparison of numbers of fungal and bacterial colonies growing on PDAA dishes seeded with wheat washes treated with $\mathrm{pH}$ 2.5-buffered water, and untreated controls, indicated that acidic conditions in conjunction with antibiotics eliminated 46 to $87 \%$ of fungi and more than $99 \%$ of bacteria, respectively, while both AEW and $0.4 \% \mathrm{NaOCl}$ treatments eliminated $100 \%$ of both bacteria and fungi (Fig. 1).

Differences in $\mathrm{pH}$ (2.64 to 2.78) and ORP $(1,091$ to 1,135$)$ among AEW preparations ranging in age from 0 to 34 days were negligible (Table 5). Free chlorine content, however, decreased from 15 to 5 ppm during the 34-day aging period. Regardless of solution age at the time of use, the numbers of fungal and bacterial colonies on petri dishes after 5 days of incubation did not vary among treatments and indicated near absolute eradication. After 5 weeks of incubation, dishes seeded with

Table 3. Numbers of fungi and bacteria CFU present in soil extracts after treatment with acidic electrolyzed water (AEW) or sodium hypochlorite $(\mathrm{NaOCl})$ and spread onto antibiotic water agar $(\mathrm{AWA})^{\mathrm{a}}$

\begin{tabular}{|c|c|c|c|c|c|c|c|c|}
\hline \multirow[b]{2}{*}{ Soil lot ${ }^{b}$} & \multicolumn{2}{|c|}{ Untreated } & \multicolumn{3}{|c|}{ AEW } & \multicolumn{3}{|c|}{$0.4 \% \mathrm{NaOCl}$} \\
\hline & Fungic & Bacteria $^{c}$ & Fungic & Bacteria $^{c}$ & Reduction $(\%)^{\mathrm{d}}$ & Fungic & Bacteria $^{c}$ & Reduction $(\%)^{\mathrm{d}}$ \\
\hline Arizona & 6.3 & 1.3 & 33 & 0.0 & 99.57 & 29.0 & 0.0 & 99.62 \\
\hline Georgia & 1.0 & 0.3 & 5.0 & 0.0 & 99.59 & 6.7 & 0.0 & 99.46 \\
\hline Kansas & 1.6 & 1.6 & 5.7 & 0.0 & 99.82 & 12.0 & 0.0 & 99.63 \\
\hline Maryland & 0.4 & 2.5 & 7.3 & 0.0 & 99.75 & 6.7 & 0.0 & 99.77 \\
\hline Average & 2.3 & 1.4 & 12.8 & 0.0 & 99.68 & 13.6 & 0.0 & 99.62 \\
\hline
\end{tabular}

a Nine separate 3-g soil samples for each of four soil lots were extracted by a modification of the sieving and sucrose centrifugation technique of Babadoost and Mathre (2). Three samples were treated with AEW for $30 \mathrm{~min}$ with continuous gentle rocking, three sample extracts were treated for 2 min with $0.4 \% \mathrm{NaOCl}$, and three received no treatment (control). Serial dilutions of $10^{-1}$ to $10^{-4}$ of control samples were made and undiluted and diluted samples were spread onto AWA.

b Soil lot designated by state from where obtained.

${ }^{\mathrm{c}}$ Each figure represents the average number of $\mathrm{CFU} \times 10^{3}$ of fungi and bacteria present 6 days after seeding petri dishes with extracts from three soil samples from a soil lot.

${ }^{\mathrm{d}}$ Percent reduction is average percent decrease in colony numbers for three replicate samples treated with AEW or $\mathrm{NaOCl}$ compared with the control (no treatment) samples.

Table 4. Number of fungi and bacteria CFU in soil extracts as determined on nutrient rich media after treatment with acidic electrolyzed water or sodium hypochlorite $(\mathrm{NaOCl})^{\mathrm{a}}$

\begin{tabular}{|c|c|c|c|c|c|c|c|c|c|c|}
\hline \multirow[b]{3}{*}{ Soil lot } & & & \multicolumn{4}{|c|}{30 Min AEW } & \multicolumn{4}{|c|}{$2 \mathrm{Min} 0.4 \% \mathrm{NaOCl}$} \\
\hline & \multicolumn{2}{|c|}{ Control } & \multirow[b]{2}{*}{ Fungic } & \multirow[b]{2}{*}{ Bacteria $^{c}$} & \multicolumn{2}{|c|}{ Reduction (\%) } & \multirow[b]{2}{*}{ Fungic } & \multirow[b]{2}{*}{ Bacteria $^{c}$} & \multicolumn{2}{|c|}{ Reduction (\%) } \\
\hline & Fungic & Bacteriac $^{c}$ & & & Fungi & Bacteria & & & Fungi & Bacteria \\
\hline Arizona & 3.27 & 130.00 & 50 & 467 & 98.47 & 99.64 & 77 & 2,300 & 97.64 & 98.23 \\
\hline Maryland & 0.63 & 9.33 & 6 & 12 & 99.05 & 99.87 & 7 & 1,872 & 97.12 & $79.94^{\mathrm{d}}$ \\
\hline Georgia & 0.53 & 63.36 & 5 & 41 & 99.06 & 99.94 & 6 & 1,400 & 98.89 & 97.79 \\
\hline Kansas & 2.77 & 18.00 & 27 & 19 & 99.02 & 99.89 & 25 & 400 & 99.10 & 97.78 \\
\hline Average & 1.80 & 55.16 & 22 & 135 & 98.90 & 99.84 & 29 & 1,493 & 98.19 & 93.44 \\
\hline
\end{tabular}

a Eighteen 3-g soil samples from each of four soil lots were extracted using a modification of the sieving and sucrose centrifugation technique of Babadoost and Mathre (2). Extracts were pooled and then divided into $181-\mathrm{ml}$ aliquots. Six aliquots were treated with AEW for 30 min with continuous gentle rocking, six aliquots were treated for $2 \mathrm{~min}$ with $0.4 \% \mathrm{NaOCl}$, and six aliquots received no treatment (control). Three aliquots, or dilutions made from the aliquots, were spread onto single dishes of potato dextrose agar containing ampicillin sodium salt and streptomycin sulfate (PDAA) at 100 $\mathrm{mg} / \mathrm{liter}$ each and three onto single dishes of nutrient broth yeast agar containing cycloheximide (NBYC) at $200 \mathrm{mg} / \mathrm{liter}$ per treatment per soil lot.

b Percent reduction is the average percent decrease in CFU for three replicate samples treated with $\mathrm{AEW}$ or $\mathrm{NaOCl}$ compared with the control (no treatment) samples.

${ }^{c}$ Each figure represents the average number of $\mathrm{CFU} \times 10^{3}$ present 5 days after seeding petri dishes with three aliquots of soil extract onto PDAA for fungi or NBYC for bacteria and incubating at $20^{\circ} \mathrm{C}$.

${ }^{\mathrm{d}}$ When this experiment was repeated exactly as before, the percent reduction was $99.6 \%$. 
wheat sample debris treated with the 34day-old AEW had developed four to five fungal or bacterial colonies per 50-g wheat sample. Increases in microbial colonies did not occur with the 0- to 15-day-old AEW treatments.

\section{DISCUSSION}

When teliospores suspected of being $T$. indica are found in wheat samples, often they will not germinate (3). This is most common with young, dormant teliospores of $T$. indica found in newly harvested grain and can make confirmation by molecular methods difficult, or impossible, when only small numbers are present (5). After the discovery of Karnal bunt in Arizona and California in 1996, it was desirable to develop a method to stimulate germination and increase germination percentages in order to allow teliospore identification in those areas of the country where fungi similar to $T$. indica exist. Teliospore germination was necessary in order to obtain adequate amounts of DNA for reliable identification by PCR $(9,26)$. Any acceptable method required little or no contamination by other microorganisms when teliospores extracted from wheat seed were spread onto growth media.

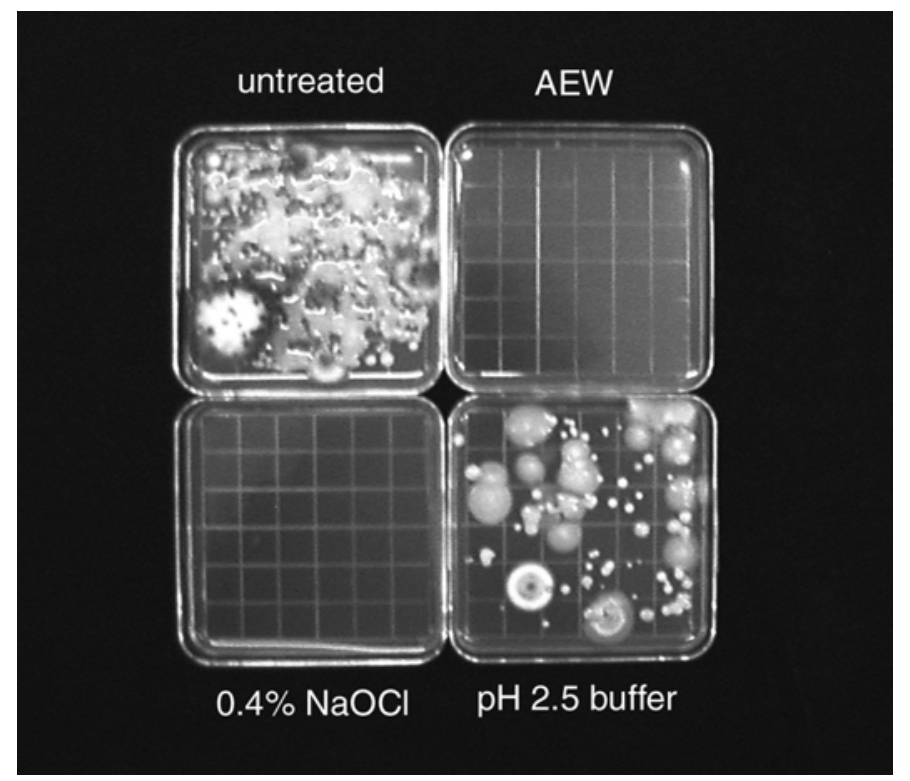

Fig. 1. Growth on potato dextrose agar (supplemented with ampicillin sodium salt and streptomycin sulfate, each at $100 \mathrm{mg} / \mathrm{liter}$ ) 5 days after seeding dishes with a wheat extract treated $30 \mathrm{~min}$ with acidic electrolyzed water (AEW), 30 min with $0.05 \mathrm{M} \mathrm{pH} 2.5$ glycine- $\mathrm{HCl}$ buffer, 2 min with $0.4 \%$ $\mathrm{NaOCl}$, or no treatment to serve as a control. Note that no growth occurred with the AEW and $0.4 \%$ $\mathrm{NaOCl}$ treatments, and that low $\mathrm{pH}$ by itself reduced growth when compared with no treatment.

Table 5. Effects of age of acidic electrolyzed water (AEW) on $\mathrm{pH}$, oxidation-reduction potential (ORP), free chlorine $\left(\mathrm{Cl}_{2}\right)$ content, and CFU of fungi and bacteria 5 days after spreading on medium ${ }^{\mathrm{a}}$

\begin{tabular}{|c|c|c|c|c|c|}
\hline \multirow[b]{2}{*}{ Treatment } & \multirow[b]{2}{*}{ pH } & \multirow[b]{2}{*}{ ORP $(\mathbf{m V})$} & \multirow[b]{2}{*}{ Free $\mathrm{Cl}_{2}(\mathrm{PPM})^{\mathrm{b}}$} & \multicolumn{2}{|c|}{ CFU } \\
\hline & & & & Fungi & Bacteria \\
\hline \multicolumn{6}{|l|}{ Age of AEW (days) } \\
\hline 0 & 2.78 & 1,129 & 15.3 & 0.3 & 0.0 \\
\hline 1 & 2.70 & 1,130 & 13.5 & 0.3 & 0.0 \\
\hline 2 & 2.71 & 1,131 & 14.2 & 0.3 & 0.3 \\
\hline 6 & 2.66 & 1,135 & 14.6 & 0.6 & 0.0 \\
\hline 10 & 2.66 & 1,125 & 10.7 & 0.3 & 0.0 \\
\hline 13 & 2.64 & 1,121 & 9.0 & 0.3 & 0.0 \\
\hline 15 & 2.65 & 1,119 & 10.3 & 1.0 & 0.0 \\
\hline 34 & 2.65 & 1,091 & 4.6 & 0.3 & 0.0 \\
\hline $0.4 \% \mathrm{NaOCl}$ (fresh) & $\ldots$ & $\ldots$ & $\ldots$ & 1.3 & 0.3 \\
\hline Control $^{\mathrm{d}}$ & $\ldots$ & $\ldots$ & $\ldots$ & TNTC & $\ldots$ \\
\hline
\end{tabular}

a Thirty 50-g samples of durum wheat (cv. Renville) were washed using size-selective sieving (21), and the washes were pooled and redivided. After incubation overnight at $20^{\circ} \mathrm{C}$, three redivided washes were treated with AEW of each age for 30 min with continuous rocking, three were treated with $0.4 \% \mathrm{NaOCl}$ for $2 \mathrm{~min}$, and three received no treatment. Washes were spread onto potato dextrose agar containing ampicillin sodium salt and streptomycin sulfate (PDAA) at $100 \mathrm{mg} / \mathrm{liter}$ each, and $\mathrm{CFU}$ of fungi and bacteria were determined after 5 days.

${ }^{\mathrm{b}}$ Free chlorine content was determined by spectrophotometric analysis at $528 \mathrm{~nm}$ using $N, N$-diethyl$p$-phenylenediamine.

c AEW was aged at room temperature in glass bottles for the number of days indicated.

${ }^{\mathrm{d}}$ Control $=$ no treatment; TNTC $=$ too numerous to count .

In a previous study, AEW was shown to both stimulate $T$. indica teliospore germination and prevent growth of other microorganisms present in seed washings being tested for the presence of Karnal bunt teliospores (3). However, the level of germicidal effectiveness was not determined. AEW was superior to $\mathrm{NaOCl}$ for disinfesting teliospores because teliospores could be in contact with the disinfestant for up to $2 \mathrm{~h}$ without being killed (3). In contrast, treatments longer than 2 min with $0.4 \% \mathrm{NaOCl}$ greatly reduced teliospore germination and, by $10 \mathrm{~min}$, few viable spores were found (3). The critical timing of $\mathrm{NaOCl}$ removal following treatment reduced its usefulness as a teliospore disinfestant and germination stimulant. For example, in teliospore longevity studies, any delay in removing $\mathrm{NaOCl}$ would jeopardize confidence in the data. A lack of, or low, germination rate would raise the question as to whether the disinfestation process itself might have killed the teliospores. AEW appears not to reduce germination, even when teliospores had been in soil for several years, lost their protective sheath surrounding the exterior of each teliospore, and become partially degraded (M. R. Bonde and S. E. Nester, unpublished).

The study described here was designed to quantitate and compare the effectiveness of $\mathrm{AEW}$ and $0.4 \% \mathrm{NaOCl}$ in eradicating nonbunt microorganisms from wheat seed or soil samples. To provide the most accurate measurements, $T$. indica teliospores initially were intentionally absent from the test samples. The use of these mock samples simplified enumeration of nonbunt microorganisms and allowed a rapid determination of CFU of bacteria and fungi because $T$. indica teliospores, which survive AEW treatment, were absent. When teliospores were present and germinated, large numbers of sporidia produced secondary colonies which overgrew nonbunt colonies.

When we spread AEW-treated extracts from $T$. indica-teliospore-infested soil onto $2 \%$ water agar petri dishes with antibiotics, approximately $88 \%$ of dishes remained completely free of contaminants. Of contaminated dishes, only one to three contaminant colonies were present per dish and, thus, rarely affected $T$. indica colony counts.

Size-selective sieving eliminates large and small debris by selecting only particles between 20 and $53 \mu \mathrm{m}$ in size, which reduces the amount of total contaminants. Large-sized debris, in particular, contains contaminants difficult to rid with disinfestants (21). The fine debris that does pass through the $53-\mu \mathrm{m}$ screen and subsequently is trapped on a $20-\mu \mathrm{m}$ screen contains $T$. indica teliospores, along with considerable debris. When this selected debris is treated with AEW, diluted, and plated onto AWA, the presence of antibiotics and minimal nutrient condition of the germination 
medium combine to reduce growth of much of the remaining contamination.

The protocol developed and described in this presentation for surface sterilization was based on a volume of AEW to material being treated of at least 30:1. Smaller volumes of AEW in preliminary experiments were not as effective (data not presented). AEW apparently was consumed during disinfestation. Most bacteria easily are controlled by antibiotics and do not grow well on water agar; therefore, AEW's greatest benefit is its ability to prevent contaminating fungal growth. We repeatedly observed that $>99.99 \%$ of fungal propagules were eliminated by the AEW treatment alone. With the additional reduction by dilution, and the use of AWA, contamination on petri dishes was rarely a problem.

Decontamination of seed samples usually was more thorough than soil, perhaps because less debris was present in seed samples to absorb or alter constituents of AEW that are germicidal. However, in an experiment in which we tested AEW before and after it was used to treat wheat seed extracts and soil extracts, $\mathrm{pH}$ and ORP changed little (data not presented). The free chlorine content generally decreased by about $50 \%$. With one dirty seed sample, however, the free chlorine content decreased to nearly $0 \%$.

AEW, a form of "electrolyzed water", has several benefits over $\mathrm{NaOCl}$. AEW reverts to near normal water after use; therefore, it is considered environmentally safe and does not pose a disposal problem (3). It can be produced inexpensively in small or large quantities and stored for several days in closed containers, as demonstrated in this study. Use of AEW presents no known hazards to workers, because concentrations of chlorine compounds are low. In contrast, $\mathrm{NaOCl}$ can give off dangerous chlorine fumes, posing a risk to human health in large decontamination projects (31). Also, $\mathrm{NaOCl}$ cannot be used for long periods with metal containers due to corrosion (31).

In order to determine the active shelf life of AEW, a component of its potential usefulness, we conducted a study in which we compared activity of AEW of different ages ranging from 0 to 34 days. We were interested mostly in its effectiveness at preventing fungal growth; therefore, we spread treated wheat seed washes onto PDAA to eliminate bacteria and, thus, tested specifically for fungal growth. Fifteen-day-old AEW was as effective at preventing fungal growth as fresh AEW (Table 5). By 34 days, when AEW was still effective, the $\mathrm{pH}$ and ORP had changed only slightly, whereas the content of free chlorine had decreased from 15 to $5 \mathrm{ppm}$. We concluded that AEW was fungicidal, not fungistatic, because treated samples on PDAA could be held up to at least 5 weeks with no microbial growth.
It is important to realize that there are two types of electrolyzed water generators and their products are not equal. One type produces "neutral electrolyzed water", of approximately $\mathrm{pH}$ 6.8, from a dilute solution of sodium chloride in a single chamber $(15,16)$. The second type, used in this study, produces an acid water at approximately $\mathrm{pH} 2.5$, here termed AEW, in an anode chamber, and alkaline water in a cathode chamber $(3,29,30)$.

Although neutral electrolyzed water has sterilizing properties, AEW appears to be a more effective sanitizer when neutral electrolyzed water $(15,16,33)$ and AEW $(3,13,14,28-30$; this study) are compared. Venkitanarayanan et al. (30) produced AEW at $\mathrm{pH} 2.4$ to 2.6, free chlorine of 40 to $85 \mathrm{ppm}$, and ORP of $1,150 \mathrm{mV}$ and obtained a $7 \log _{10}$ reduction in CFU for three bacterial species tested. In another study in which meat cutting boards were treated with electrolyzed water at $\mathrm{pH} 2.5$, ORP of $1,150 \mathrm{mV}$, and free chlorine content of 85 to $90 \mathrm{ppm}$, Venkitanarayanan et al. reported a $5 \log _{10} \mathrm{CFU}$ reduction in bacterial populations and attributed this reduction to hypochlorous acid (29). The AEW we used had a $\mathrm{pH}$ of 2.5 to 2.8 , ORP of $1,150 \mathrm{mV}$, and free chlorine content of $15 \mathrm{ppm}$, and a 6 to $7 \log _{10}$ reduction in CFU of bacteria and fungi was obtained.

One factor for AEW being more germicidal may be the highly acidic condition of AEW. In our study, we demonstrated that the low $\mathrm{pH}$ of AEW by itself could account for 46 to $87 \%$ of the reduction of fungi, and as much as $99 \%$ of bacteria. It has long been known that acid conditions destroy bacteria, and that weak acids, such as hypochlorous acid $(\mathrm{pKa}=7.5)(31)$, are more bactericidal than strong acids (27).

For the purpose of treating $T$. indica teliospores extracted from either 50-g wheat seed samples by size-selective sieving (21), or 3-g soil samples by sieving and the sucrose centrifugation as described here, we routinely used the following procedure: (i) suspend wheat or soil extracts in sterile distilled water in $15-\mathrm{ml}$ centrifuge tubes and incubate overnight at $20^{\circ} \mathrm{C}$; (ii) centrifuge at $1,200 \times g$ for $3 \mathrm{~min}$, decant, and discard supernatant; (iii) add $14 \mathrm{ml}$ of AEW to the pellet and resuspend; (iv) rock suspension gently on a Speci-mix (Barnstead/Thermolyne) or comparable rocker for $30 \mathrm{~min}$; (v) centrifuge at 1,200 $\times$ $g$ for $3 \mathrm{~min}$, decant, and discard supernatant; (vi) add $14 \mathrm{ml}$ of sterile distilled water and resuspend the pellet; (vii) centrifuge at $1,200 \times g$ for $3 \mathrm{~min}$, decant, and discard supernatant; and (viii) resuspend the pellet in sterile distilled water to the desired dilution to spread onto the appropriate medium.

In spite of the great sanitizing benefits of AEW, it is not the answer to all sanitizing needs, but is an attractive alternative when selective sterilization is desired. For reliable PCR identification using isolated teliospores, maximum germination of Karnal bunt teliospores and elimination of other microorganisms is desired. The described AEW practice now routinely is used in our laboratory to isolate and germinate $T$. indica teliospores from wheat seed and soil samples.

\section{ACKNOWLEDGMENTS}

We thank J. Smilanick and B. Goats for many helpful suggestions throughout the study and critical review of the manuscript; G. FuentesDavila for providing the source of teliospores from Sonora, Mexico; E. Alexander for providing the electrolysis apparatus to generate AEW and guidance in its use; and the late A. Khayat for suggesting the use of AEW for treating Karnal bunt teliospores.

\section{LITERATURE CITED}

1. American Phytopathological Society. 1996. Position statement. The American Phytopathological Society: The use of quarantines for wheat Karnal bunt. Karnal bunt symposium. Published online: APSnet.

2. Babadoost, M., and Mathre, D. E. 1998. A method for extraction and enumeration of teliospores of Tilletia indica, T. controversa, and T. barclayana in soil. Plant Dis. 82:13571361.

3. Bonde, M. R., Nester, S. E., Khayat, A., Smilanick, J. L., Frederick, R. D., and Schaad, N. W. 1999. Comparison of effects of acidic electrolyzed water and $\mathrm{NaOCl}$ on Tilletia indica teliospore germination. Plant Dis. 83:627-632.

4. Bonde, M. R., Nester, S. E., Smilanick, J. L., Frederick, R. D., Schaad, N. W., and Luster, D. G. 1999. Use of acidic electrolyzed water to obtain axenic cultures of Tilletia indica from wheat or soil samples. (Abstr.) Phytopathology 89:S8.

5. Bonde, M. R., Peterson, G. L., Schaad, N. W., and Smilanick, J. L. 1997. Karnal bunt of wheat. Plant Dis. 81:1370-1377.

6. Castlebury, L. A., and Carris, L. M. 1999. Tilletia walkeri, a new species on Lolium multiflorum and L. perenne. Mycologia 91:121131.

7. Crous, P. W., Van Jaarsveld, A. B., Castlebury, L. A., Carris, L. M., Frederick, R. D., and Pretorius, Z. A. 2001. Karnal bunt of wheat newly reported from the African continent. Plant Dis. 85:561.

8. Durán, R. 1972. Further aspects of teliospore germination in North American smut fungi. Can. J. Bot. 50:2569-2573.

9. Ferreira, M. A. S. V., Tooley, P. W., Hatziloukas, E., Castro, C., and Schaad, N. W. 1996. Isolation of species-specific mitochondrial DNA sequence for identification of Tilletia indica, the Karnal bunt of wheat fungus. Appl. Environ. Microbiol. 62:87-93.

10. Frederick, R. D., Snyder, K. E., Tooley, P. W., Berthier-Schaad, Y., Peterson, G. L., Bonde, M. R., Schaad, N. W., and Knorr, D. A. 2000 Identification and differentiation of Tilletia indica and T. walkeri using the polymerase chain reaction. Phytopathology 90:951-960.

11. Fuentes-Davila, G. 1998. Karnal bunt of wheat. Pages 69-81 in: Proc. Bunts and Smuts of Wheat Int. Symp. Triangle Park, NC. North American Plant Protection Organization, Ottawa, Canada.

12. Gomori, G. 1955. Preparation of buffers for use in enzyme studies. Pages 138-146 in: Methods in Enzymology, S. P. Colowick and N. O. Kaplan, eds. Academic Press, Inc., New York.

13. Hayashi, H., Kumon, K., Yahagi, N., Haruna, M., Watanabe, Y., Matsui, J., and Hattori, R. 1997. Successful treatment of mediastinitis after cardiovascular surgery using elec- 
trolyzed strong acid aqueous solution. Artif. Organs 21:39-42.

14. Horton, A. R., Hung, Y-C., Venkitanarayanan, K., Ezeike, G. O. I., and Doyle, M. P. 1999. Efficacy of electrolyzed oxidizing water in inactivating E. coli 0157:H7 on apples. In: Activities Rep. R \& D Associates. Research and Development Associates for Military Food and Packaging Systems. 1998/1999. V 50/51:231-233.

15. Izumi, H. 1999. Electrolyzed water as a disinfectant for fresh-cut vegetables. J. Food Sci. 64:536-539.

16. Izumi, H., Kiba, T., and Hashimoto, S. 1999. Efficacy of electrolyzed water as a disinfectant for fresh-cut spinach. Australian Centre for International Agricultural Research (ACIAR) Postharvest Newsl. No. 50, Item 28.

17. Kumon, K. 1997. What is functional water? Artif. Organs 21:2-4.

18. McPherson, L. L. 1993. Understanding ORP's role in the disinfection process. Water Eng. Manage. 140:29-31.

19. Melching, J. S., Bromfield, K. R., and Kingsolver, C. H. 1983. The plant pathogen containment facility at Frederick, Maryland. Plant Dis. 67:717-722.

20. Mitra, M. 1931. A new bunt of wheat in India. Ann. Appl. Biol. 18:178-179.

21. Peterson, G. L., Bonde, M. R., and Phillips, J. G. 2000. Size-selective sieving for detecting teliospores of Tilletia indica in wheat seed samples. Plant Dis. 84:999-1007.

22. Schaad, N. W. 2001. Initial identification of common genera. Pages 1-15 in: Laboratory Guide for Identification of Plant Pathogenic Bacteria, third ed. American Phytopathological Society Press, St. Paul, MN

23. Schaad, N. W., Bonde, M. R., and Hatziloukas, E. 1997. Bio-PCR: a highly sensitive techniques for detecting seedborne fungi and bacteria. Pages 159-164 in: Seed Health Testing. J. P. Hutchins and J. C. Reeves, eds. CAB International, Wallingford, UK.

24. Shiba, A., and Shiba, K. 1995. Strong Ionized Water Handbook. Department of Dentistry. Showa University and Department of Dentistry, Tokyo Medical and Dental University. Igoku Joho Co. Ltd., Tokyo, Japan.

25. Smilanick, J. L., Hoffman, J. A., Secrest, L. R., and Wiese, K. 1988. Evaluation of chemical and physical treatments to prevent germination of Tilletia indica teliospores. Plant Dis. 72:46-51.

26. Smith, O P Peterson, G. L. Beck, R J Schaad, N. W., and Bonde, M. R. 1996. Development of a PCR-based method for identification of Tilletia indica, causal agent of Karnal bunt of wheat. Phytopathology 86:115-122.

27. Stamier, R. Y., Dandoroff, M., and Adelberg, E. A. 1963. Pages 353-354 in: The Microbial World, 2nd ed. Prentice-Hall, Inc., Englewood Cliffs, NJ.
28. Tanaka, H., Hirakata, Y., Kaku, M, Yoshida R., Takemura, H., Mizukane, R., Ishida, K. Tomono, K., Koga, H., Kohno, S., and Kamihira, S. 1996. Antimicrobial activity of super oxidized water. J. Hosp. Infect. 34:43-49.

29. Venkitanarayanan, K. S., Ezeike, G. O. I., Hung, Y.-C., and Doyle, M. P. 1999. Inactivation of Escherichia coli 0157:H7 and Listeria monocytogenes on plastic kitchen cutting boards by electrolyzed oxidizing water. J. Food Prot. 62:857-860.

30. Venkitanarayanan, K. S., Ezeike, G. O. I Hung, Y.-C., and Doyle, M. P. 1999. Efficacy of electrolyzed oxidizing water for inactivating Escherichia coli 0157:H7, Salmonella enteritidis, and Listeria monocytogenes. Appl. Environ. Microbiol. 65:4276-4279.

31. White, G. C. 1992. Handbook of Chlorination and Alternative Disinfectants. Van Nostrand Reinhold, New York.

32. Wilk, I. J., Altmann, R. S., and Berg, J. D. 1987. Antimicrobial activity of electrolyzed saline solutions. Sci. Total Environ. 63:191197.

33. Yang, S., Li, Y-, and Slavik, M. F. 1999. Antibacterial efficacy of electrochemically activated solution for poultry spraying and chilling. J. Food Sci. 64:469-472.

34. Ykema, R. E., Floyd, J. P., Palm, M. E., and Peterson, G. L. 1996. First report of Karnal bunt of wheat in the United States. Plant Dis. 80:1207. 